\title{
Achieving ecological restoration by working with local people: a Chinese scholar seeks win-win paths
}

$\underline{H e r a n}_{\text {Zheng }}{ }^{1}$ and Guosheng Wang $^{2}$

\begin{abstract}
Environmental degradation and poverty are linked, and this means that conservation and poverty reduction must be tackled together. However, finding a successful integrated strategy has been an elusive goal. We describe the career of a Chinese scholar, Shixiong Cao, whose persistent efforts to find and follow win-win paths have led to ecological restoration accompanied by long-term benefits for local residents. Cao's story illustrates how development that combines environmental and economic perspectives can both help people to escape the poverty trap and restore degraded environments. His experience demonstrates that when environmental managers find solutions that can mitigate or eliminate poverty through the development of green enterprises, they can combine them with environmental restoration efforts to produce long-term sustainable solutions. In this paper, we share Cao's 28 years of experience because we believe that his scientific and practical spirit, and his belief that it is necessary to work directly with the people affected by environmental projects, will inspire other scholars and practitioners to achieve similar successes.
\end{abstract}

Key Words: environmental conservation; environmental policy; poverty trap; scientific philosophy; socioeconomic development

\section{INTRODUCTION}

The complexity of coupled natural and human systems has been increasingly emphasized in studies of natural resource management (Agrawal 2003, Berkes et al. 2003), especially in the context of ecological restoration and conservation projects (Liu et al. 2007, Cao 2011). The positive or negative feedback from the human system directly determines the success or failure of these projects. The interaction between poverty and environmental degradation can create a vicious circle in which poverty leads to environmental degradation and environmental degradation deepens poverty; this is known as the poverty trap (Cao et al. $2009 a$ ). Hence, considering the people who are affected by a project and accounting for their needs during the project are critical to achieve both the ecological goal and social progress (Xu et al. 2005, Cao 2011). Win-win projects that result in both conservation and economic gains are not easy to implement, although they are a commendable goal (Tallis et al. 2008). Finding the best approaches and implementation strategies to achieve these goals has become a subject of intense debate in recent years (Adams et al. 2004).

During his 28 years of scientific research and operational practice in China's most ecologically fragile and economically impoverished regions, from arid northwestern China to wet southern China, Shixiong Cao devoted himself to looking for a win-win path for ecological restoration. His career illustrates how development that combines environmental and economic perspectives and that provides appropriate compensation to affected populations can improve both nature and society, thereby eradicating the poverty trap. His story reveals how the ecologist's worldview, when combined with a profound respect for human society and human institutions, can be used to find ways to achieve harmony between humans and the environment, and provides examples to inspire other researchers and environmental managers.

\section{FROM PRACTICE TO HYPOTHESIS}

A journey from belief to doubt

Shixiong Cao (Fig. 1) was born in 1965. Like most Chinese people of this era, he was brought up in a rural village, located in Shaanxi Province on the Loess Plateau of north-central China. In childhood, Cao witnessed large, ambitious programs of deforestation and cultivation on slopes for grain production and exacerbation of poverty by the resulting land degradation. These events profoundly shaped his worldview and guided his career choice. After graduation in 1985 from university, Cao devoted his efforts to the Xingzihe River Watershed project, which was funded by the United Nations World Food Program. The goal was to restore the watershed's ecology through afforestation and ecological engineering such as soil-check dams. Although the project received an award from China's Minister of Agriculture when it ended and Cao received an award from the World Food Program for improving the seeding technology in arid and semiarid areas, there was no mechanism to address how the ecological restoration affected the local people, resulting in little or no improvement of local conditions. He gradually realized that ecological restoration without consideration of economic conditions cannot eradicate environmental problems.

If local conditions cannot be improved by a project, those affected may be forced to return to their old ways of making a living, such as deforestation and cultivation on slopes, particularly when the success of a project depends on the availability of government subsidies that disappear when the project ends. After thousands of conversations with poor people, Cao began to suspect that poverty resulted from poor government choices, such as an overreliance on technology. During this period, he tried to develop rural regions through a combination of science and education and to industrialize soil and water conservation in an effort to reconcile the needs of the local people with those of the restoration projects. However, it remained unclearhow to create the capacity for long-term improvement of local livelihoods and

${ }^{1}$ College of Economic Management, Beijing Forestry University, ${ }^{2}$ China Law Society 
Fig. 1. Shixiong Cao works both as an engineer who monitors the results of ecological restoration (Top) and as a social scholar who visits and teaches farmers in his spare time (Bottom).

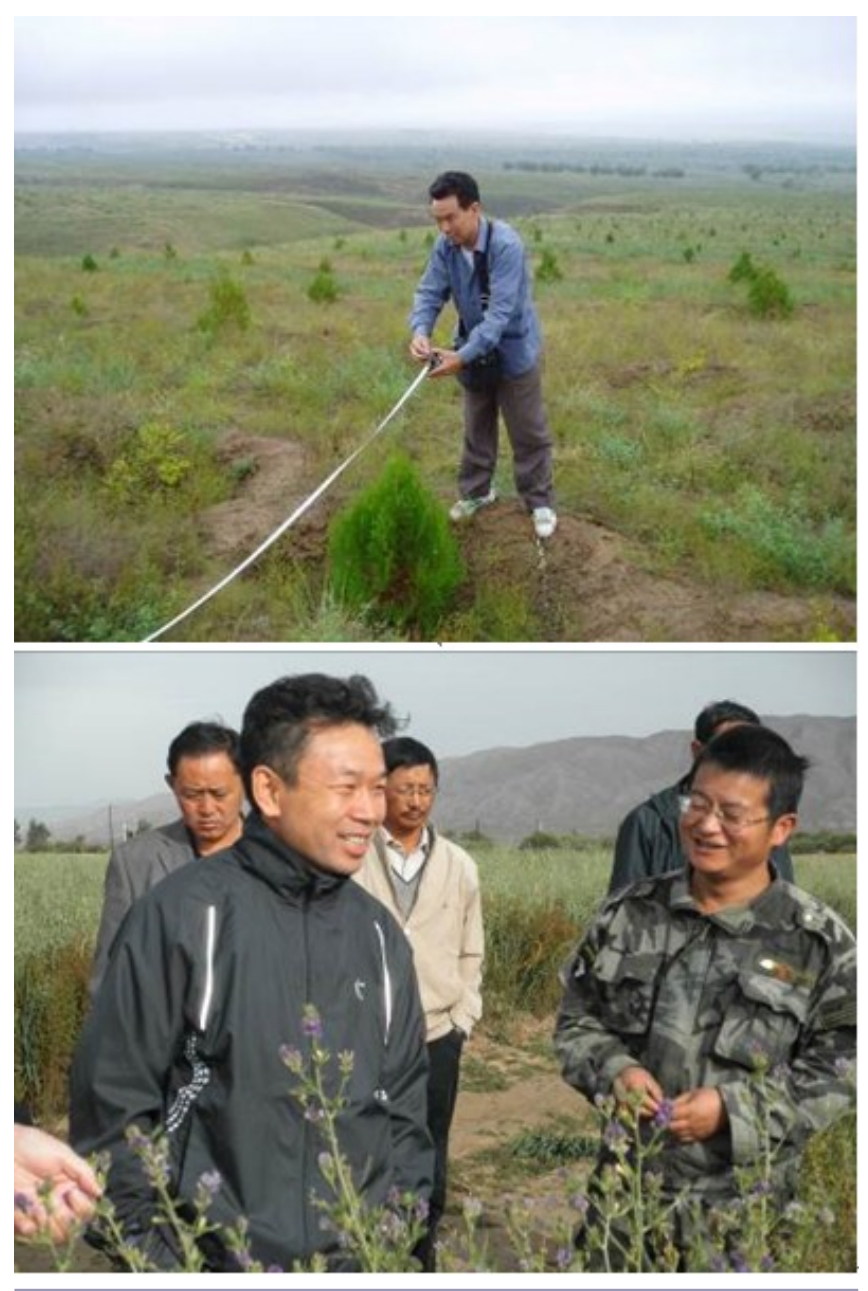

how to establish patterns that would help people to escape the poverty trap.

\section{Openness of thought and clear explanations}

When the World Food Program project ended, Cao participated in the Soil and Water Conservation in the Yanhe River Watershed project as project engineer from 1994 to 2002, which provided opportunities to experiment with new approaches and practices that would shape his future career. The program was part of the Loess Plateau project funded by the World Bank in an effort to restore the watershed's environment, optimize land use and resource allocation, and reduce soil erosion, but remarkably, it also emphasized improvement of the livelihoods of local people. During his research, Cao found that measures that would directly increase income, such as planting of orchards, terrace construction, planting of fuelwood forests, and establishment of irrigated land, were broadly accepted by local residents. However, purely ecological measures such as seeding and the construction of soil-check dams that could not increase incomes and were likely to produce only short-term gains were not broadly accepted because of the weakness of the local livestock industry and the low annual precipitation, which made the soil-check dams ineffective.

The traditional methods of agricultural engineering that Cao had learned in school were often difficult to adapt to the complex natural backgrounds where they were implemented, especially in regions with high soil and water losses. He attempted to develop agricultural patterns that permitted more economical agriculture in hilly regions while also achieving soil and water conservation. This work led to the development of improved terraces, orchards, grasslands, and even roads that were better adapted to local environmental conditions and were widely accepted. During the period, annual grain production increased by $30 \%$ and net income increased by $250 \%$. Although this project was praised by the World Bank and the Chinese government, Cao was dissatisfied and worried about subsequent plans for socioeconomic development when the project ended.

To understand the attitudes of participants in ecological restoration programs, Cao organized an investigation in northern China's Shaanxi province to learn about the land-use changes that have occurred under two major national programs that were launched by the central government in 2000: the Grain for Green Project and the Natural Forest Conservation Program. Cao et al. $(2009 b)$ found that the livelihoods of local residents were often greatly disturbed by these projects; because the compensation programs were not adequately adapted to local needs, $35 \%$ of farmers, $47 \%$ of livestock grazers, and $60 \%$ of forest workers felt that their livelihood had been adversely affected by the projects. Moreover, a lack of training to develop new skills and a lack of alternative forms of employment made it likely that as soon as the funding provided by these programs ended, many, perhaps most, of these people would be forced to return to their old activities to survive (Cao et al. 2010).

Many evaluations of the effectiveness of ecological restoration projects have relied entirely on qualitative or short-term assessments by scientists and managers from central and local governments, who have a vested interest in reporting positive results rather than relying on carefully controlled, long-term, field-based monitoring and quantitative studies to ensure the success of their efforts (Shi and Rao 2010). China's current ecological restoration system, which is mainly implemented by the central government, pays little attention to development of an ecological economy that would sustain local residents' livelihoods after the restoration program ends. There also is no follow-up to ensure that the ecological restoration is maintained when the project ends. Projects desired by government are often unattractive to the farmers, loggers, fishers, and others who manage ecosystems directly, especially when the project ends (Wunder et al. 2008, Cao 2011). Although the Yanhe River project provided a good model for interaction with local people and support for development of new industries, such interactions were weak in the larger national projects because of the huge area affected and the relatively low per capita investment, which made it difficult to establish and sustain industries to replace those that were eliminated by the projects.

The experience in the Yanhe River project confirmed the belief that the key to successful ecological restoration is to develop the 
rural economy in ways that create harmony between humans and the environment, that is, to follow a win-win path. Policy makers have to develop resource plans that account for the unique characteristics of the local environment and the needs of residents affected by the plans; in other words, it is necessary to recognize the important role of agricultural products and other natural resources by explicitly planning for economic development, such as the establishment of new industries, after implementation of the plan (Cao et al. 2009a). In addition, education of the stakeholders and ongoing consultation between local residents at the grassroots level and policy makers are essential for finding a win-win path. This path provides a model for achievement of harmony between humans and their environment.

\section{FROM HYPOTHESIS TO PRACTICE}

In 2002, Cao began to cooperate with Changting County, which is located in the western Fujian Province, to implement a new ecological restoration project designed to practice the win-win strategy beginning at the blueprint stage (Fig. 2). In the past, the county was covered with vegetation because of high precipitation and warm temperatures. However, a half-century of intensive deforestation and monoculture planting led to large declines in biodiversity and vegetation cover, exacerbating the frequency and extent of soil erosion and increasing the severity of floods, which led to landscape degradation and made the county one of China's most poverty-stricken regions (Fig. 2, Top). Changting County's population was growing fast despite low levels of urbanization, a poor transportation infrastructure, and a weak industrial tradition. Moreover, the unsustainable use of natural resources exacerbated the extent and intensity of rural poverty, forcing residents to engage in low-productivity subsistence agriculture. Rural households relied on fuelwood and dried grasses for heating, cooking, and the preparation of livestock feed, which were highly vulnerable to environmental change and market fluctuations.

To alleviate the environmental degradation and poverty, the government reformed property rights by allocating forested land to individual farmers in 1985 . However, the impoverished farmers did not protect the environment as expected; on the contrary, more intensive harvest by these poor farmers resulted in worse degradation (Cao et al. 2009a). The areas of severe soil erosion were increased by more than $100 \%$ from 1985 to 1995 . The previous program was replaced by a new development program in a few experimental regions including Changting County. Cao was invited to serve as the scientific adviser to guide the project because of his rich experience.

After investigation in local households, Cao found that poverty and fuel scarcity were the most significant problems in the mountainous region. Having learned from the compensation mechanisms in the Yanhe River Project, he sought similar ways to find a win-win solution that would improve human welfare as much as the environment. He proposed that the new policy should focus on improvement of economic conditions and that the subsidy should change from an approach based on payments only for the actions to an approach based on payments to develop economic capacity. In addition, he emphasized all stakeholders should be consulted to ensure that the ecological restoration project would meet their needs.
Fig. 2. Changes in the landscape during the soil and water conservation project in Changting County in 2000 (Top) and 2008 (Bottom; Cao et al. 2009a).
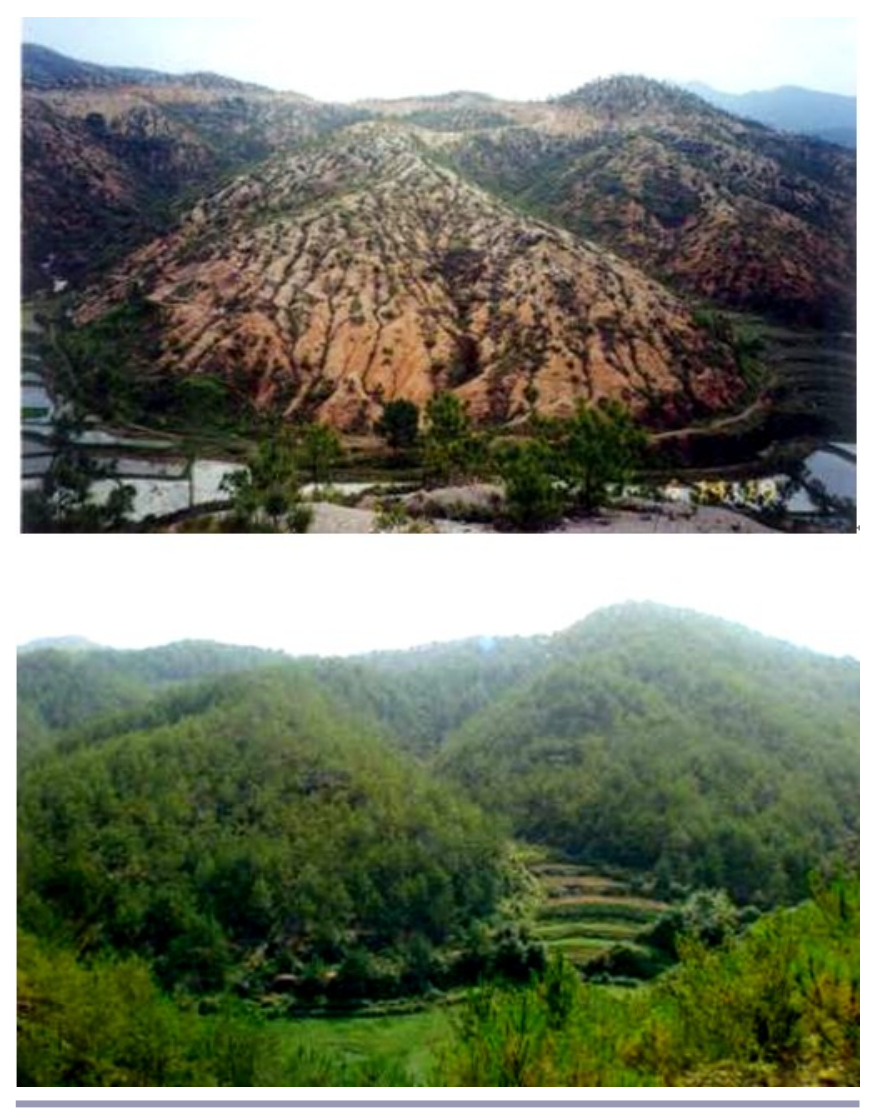

With the new policy, the government encouraged construction of methane-generation facilities and compensated these facilities for every household they served, to move the farmers away from harvesting wood for fuel. The government also encouraged through compensation the large number of activities that would increase net income, such as planting fruit trees, using organic fertilizer, and husbandry (Lu 2002, Cao et al. 2009a). Remarkably, the infrastructures funded by subsidies would provide persistent income and reduce costs even if the government subsidies ended, which greatly increased the likelihood that the environmental improvements would be sustainable.

Green enterprises that employ local residents in the long term without causing significant damage are essential for simultaneously alleviating poverty and achieving ecological restoration. As Cao suggested, local governments have distributed land-use rights to local residents and transferred land to local enterprises through a competitive bidding process to develop green industries such as large orchards and a livestock industry. Local government encouraged the transfer of land ownership to local residents and enterprises that were willing to plant trees or forage, and prohibited tree harvesting in all natural forests, with the exception of low-lying wastelands in hilly terrain where fruit trees could be planted. Local residents, particularly women, were employed to participate directly in ecological 
restoration projects like planting by green enterprise and local government, with suggestions and guidance by scholars such as Cao. Collaboration among governments, local residents, scholars, and green enterprises in the ecological restoration project and economic development encouraged a risk-averse approach to improving resource utilization efficiency. All stakeholders could choose to participate or not in the projects, depending on their perceived benefits. It is a major change from the previous government-oriented approach, which often coerced residents to participate in the programs without considering the benefits to them. To increase the likelihood of success, Cao visited the county every year and patiently taught the government officials, farmers, students, and other participants to understand and practice a winwin strategy (Fig. 3).

Fig. 3. Shixiong Cao is a teacher who shares his knowledge in a university environment (Top), a guide who directs the students in scientific research in the field (Middle), and a consultant who shares his experience with local government managers and farmers (Bottom).
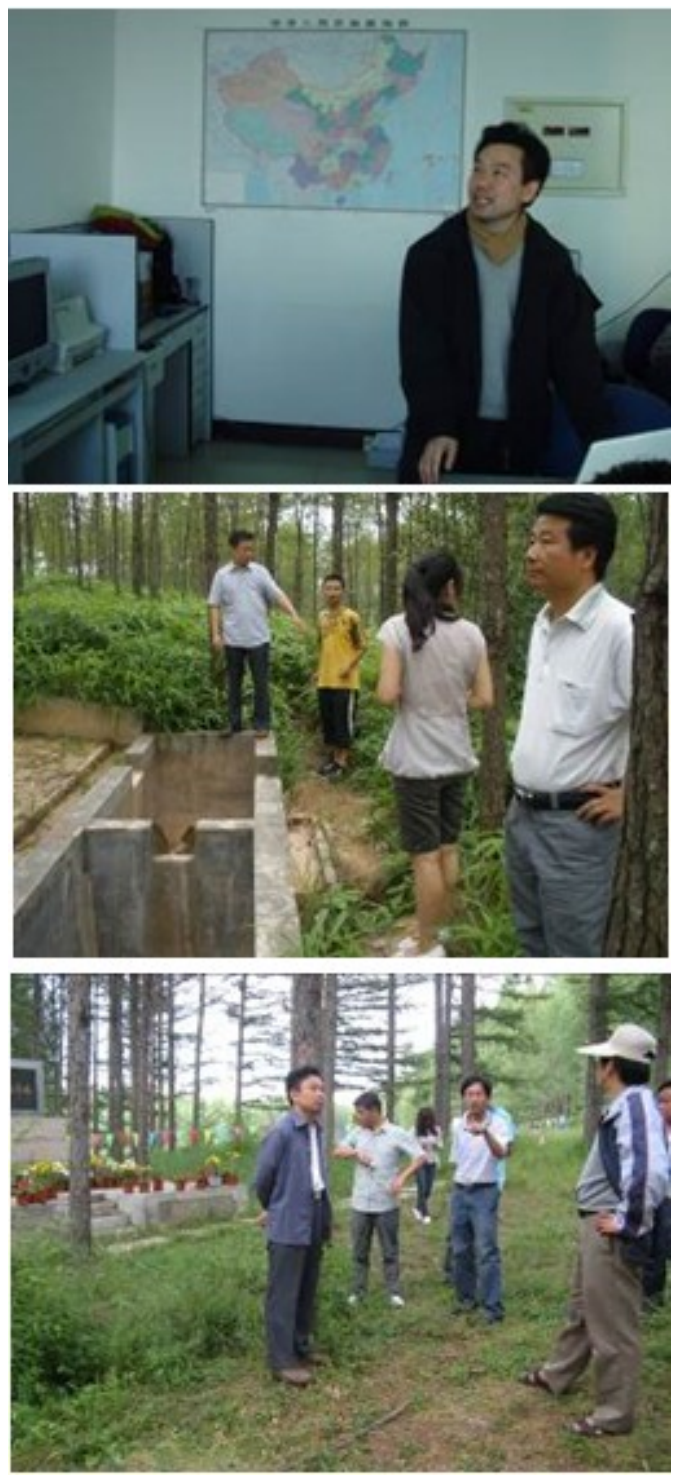

In addition, Cao also devoted time to finding the most effective strategy for vegetation recovery because of the poor effectiveness of planting. He concentrated on the degradation threshold for an ecosystem and definition of the boundary between the possibility of natural recovery and the need for artificial restoration (Gao et al. 2011). He believes that traditional ecological restoration projects rely excessively on artificial restoration such as afforestation, because the results often fail to meet expectations for a variety of reasons (Cao et al. 2009c). A failure to understand the concept of thresholds and account for their existence in restoration plans may lead to the abandonment of management efforts in areas that would otherwise benefit from interventions (Gao et al. 2011). His research provided systemic knowledge to guide artificial restoration projects and identified various vegetation restoration strategies capable of improving the efficiency and effectiveness of restoration projects in this region. The local government now has a better understanding of which areas will need artificial restoration and which can be protected to allow natural recovery. Cao is helping Changting County to develop a win-win path not only as a scientific adviser, but also as an engineer (Figs. 1 and 3). To combat the natural disasters caused by soil and water erosion, such as the gully collapse (Fig. 4, Top), Cao introduced a terrace technology that combined environmental engineering with economic development (Fig. 4, Bottom). The monitoring data demonstrated that the new approach generated a huge benefit in crop yield and economic benefits to local residents (Zhong et al. 2013).

Fig. 4. The slope collapsed when vegetation could not reduce runoff and protect the soil (Top). Successful stabilization of the slope after nine years (Bottom; Zhong et al. 2013).
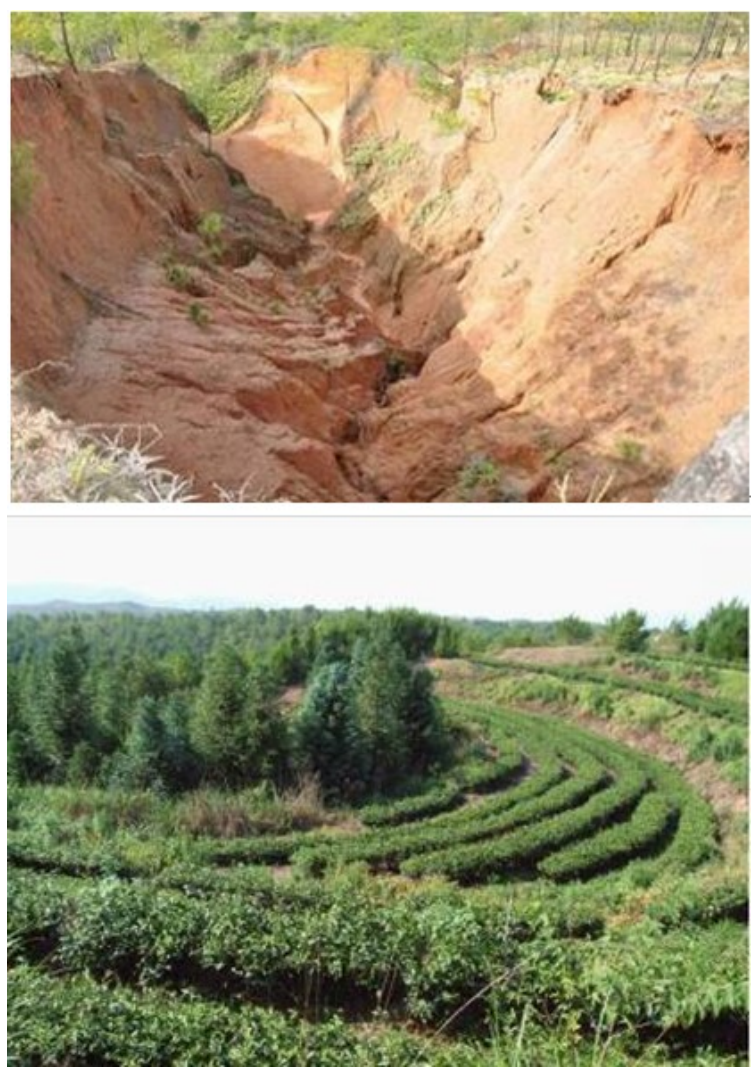
The series of methods aimed at improving economic conditions for local residents while also achieving a win for the environment have greatly improved both the environment and socioeconomic development in the project area. From 1999 to 2012, the 8194 methane-generation facilities funded by the government have greatly reduced the pressure on forests to supply fuel. The area experiencing soil erosion has decreased by $45.9 \%$, and the vegetation cover has increased by $97.6 \%$ (Fig. 2, Bottom). More than $142.6 \times 10^{3}$ local residents, more than $80 \%$ of whom were women, were employed by the government or green enterprises to perform ecological restoration work.

These successful approaches have attracted considerable attention both in China and abroad. When the paper by Cao et al. (2009a) on the win-win path for ecological restoration and its role in eradicating the poverty trap was published, it was chosen by the Faculty of 1000 Biology project as one of the most important biological papers of 2009. The judges noted that "This interesting case study from Changting County in China offers hope and guidance in how 'win-win' outcomes might be achieved, particularly in developing regions. This is a valuable example of the potential to address what is undoubtedly one of our most pressing problems - balancing development with conservation" (G. Luck, Article recommendations, http://f1000.com/ prime/1161593). In 2011, Chinese vice-president Xi Jinping, who is now China's president, particularly praised the efforts of Changting County in China's official media and suggested that Changting County provides an example that other governments could follow. It shows that win-win approaches to ecological restoration have been realized and emphasized by the central government. The Changting Model has earned a well-deserved reputation for innovative thinking. Although the welfare of local residents has improved and conservation goals are being achieved, Cao continues to monitor the socioeconomic changes. As he notes, conditions outside the county are changing greatly, and how to sustain the model's success is not yet clear. We believe that Cao played a critical role in achieving this success by integrating his decades of personal experience into a holistic solution that is helping Changting County succeed and recover from past failures.

\section{CONCLUSIONS}

Recovering from past failures by adopting innovative new approaches requires a combination of scientific rigor and the ability to work with governments and other stakeholders to understand and account for the true complexity of ecological restoration problems. Shixiong Cao's pioneering work to engage green enterprises, local residents, governments, and scholars in ecological restoration achieved a win both for local residents and for the environment, and increased recognition of the relationship between ecological restoration and poverty mitigation and of the importance of taking advantage of the knowledge and skills of all stakeholders. His 28 years of theoretical and practical, i.e., field, research show that successful environmental management and ecological restoration cannot occur without accounting for both the ecological and the human aspects of a problem. By focusing on secure employment for local residents, the new approach secures fundamental benefits that will prevent a return to the region's former poverty and will provide instead a sustainable future income. The development of green enterprises based on modern management techniques can mitigate the risks and uncertainties better than individual-level or household-level management based on informal business techniques. Furthermore, the status of women has been raised by these approaches, because women were key participants in the plantation program and were hired by the new green enterprises.

Cao's innovative approach is based on a combination of scientific rigor and a concern for the human condition, as demonstrated by his eagerness to work with stakeholders ranging from governments to farmers. We believe his experiences provide an inspiring example for other researchers and government managers to follow.

Responses to this article can be read online at: http://www.ecologyandsociety.org/issues/responses. $\mathrm{php} / 6995$

\section{Acknowledgments:}

We thank our colleagues in the Yanhe River World Bank Project Office and the Changting Soil and Water Conservation Bureau for their long assistance with the projects described in this paper. The Xingzihe River Watershed project was funded by the United Nations World Food Program (No. 3225), and the World Bank provided funding for the Soil and Water Conservation in the Yanhe River Watershed project (No. 3222CHA). We also thank Geoffrey Hart of Montréal, Canada, for his help in writing this paper.

\section{LITERATURE CITED}

Adams, W. M., R. Aveling, D. Brockington, B. Dickson, J. Elliott, J. Hutton, D. Roe, B. Vira, and W. Wolmer. 2004. Biodiversity conservation and the eradication of poverty. Science 306 (5699):1146-1149. http://dx.doi.org/10.1126/science.1097920

Agrawal, A. 2003. Sustainable governance of common-pool resources: context, methods, and politics. Annual Review of Anthropology 32:243-262. http://www.annualreviews.org/doi/ abs/10.1146/annurev.anthro.32.061002.093112

Berkes, F., J. Colding, and C. Folke. 2003. Navigating socialecological systems: building resilience for complexity and change. Cambridge University Press, Cambridge, UK. http://dx.doi. org/10.1017/CBO9780511541957

Cao, S. 2011. Impact of China's large-scale ecological restoration program on the environment and society in arid and semiarid areas of China: achievements, problems, synthesis, and applications. Critical Reviews in Environmental Science and Technology 41(4):317-335. http://dx.doi.org/10.1080/10643380902800034

Cao, S., L. Chen, and X. Yu. 2009c. Impact of China's Grain for Green Project on the landscape of vulnerable arid and semi-arid agricultural regions: a case study in northern Shaanxi Province. Journal of Applied Ecology 46(3):536-543. http://dx.doi. org/10.1111/j.1365-2664.2008.01605.x

Cao, S., X. Wang, Y. Song, L. Chen, and Q. Feng. 2010. Impact of the Natural Forest Conservation Program on the livelihood of local residents in northwestern China: perceptions of residents affected by the program. Ecological Economics 69(7):1454-1462. http://dx.doi.org/10.1016/j.ecolecon.2009.04.022 
Cao, S., C. Xu, L. Chen, and X. Wang. 2009b. Attitudes of farmers in China's northern Shaanxi Province towards the land-use changes required under the Grain for Green Project, and implications for the project's success. Land Use Policy 26 (4):1182-1194. http://dx.doi.org/10.1016/j.landusepol.2009.02.006

Cao, S., B. Zhong, H. Yue, H. Zeng, and J. Zeng. $2009 a$. Development and testing of a sustainable environmental restoration policy on eradicating the poverty trap in China's Changting County. Proceedings of the National Academy of Sciences of the United States of America 106(26):10712-10716. http://dx.doi.org/10.1073/pnas.0900197106

Gao, Y., B. Zhong, H. Yue, B. Wu, and S. Cao. 2011. A degradation threshold for irreversible loss of soil productivity: a long-term case study in China. Journal of Applied Ecology 48(5):1145-1154. http://dx.doi.org/10.1111/j.1365-2664.2011.02011.x

Liu, J., T. Dietz, S. R. Carpenter, M. Alberti, C. Folke, E. Moran, A. N. Pell, P. Deadman, T. Kratz, J. Lubchenco, E. Ostrom, Z. Ouyang, W. Provencher, C. L. Redman, S. H. Schneider, and W. W. Taylor. 2007. Complexity of coupled human and natural systems. Science 317(5844):1513-1516. http://dx.doi.org/10.1126/ science. 1144004

Lu, X. 2002. Discussion of the model in the wood-harvesting is prohibited and afforestation is practiced for the soil and water conservation of Changting County [Title translated from the Chinese]. Fujian Soil and Water Conservation 14(3):29-31.

Shi, Y., and Y. Rao. 2010. China's research culture. Science 329 (5996):1128. http://dx.doi.org/10.1126/science.1196916

Tallis, H., P. Kareiva, M. Marvier, and A. Chang. 2008. An ecosystem services framework to support both practical conservation and economic development. Proceedings of the National Academy of Sciences of the United States of America 105(28):9457-9464. http://dx.doi.org/10.1073/pnas.0705797105

Wunder, S., S. Engel, and S. Pagiola. 2008. Taking stock: a comparative analysis of payments for environmental services programs in developed and developing countries. Ecological Economics 65(4):834-852. http://dx.doi.org/10.1016/j. ecolecon.2008.03.010

Xu, J., E. T. Ma, D. Tashi, Y. Fu, Z. Lu, and D. Melick. 2005. Integrating sacred knowledge for conservation: cultures and landscapes in southwest China. Ecology and Society 10(2): 7. [online] URL: http://www.ecologyandsociety.org/vol10/iss2/art7

Zhong, B., S. Peng, Q. Zhang, H. Ma, and S. Cao. 2013. Using an ecological economics approach to support the restoration of collapsing gullies in Southern China. Land Use Policy 32:119-124. http://dx.doi.org/10.1016/j.landusepol.2012.10.005 